\title{
Proporção volumétrica dos constituintes do corpo lúteo de vacas Nelore nos terços inicial, médio e final da gestação
}

\author{
[Volumetric proportion of the corpus luteum of Nelore cows in the first, second and third \\ trimester of gestation] \\ P.R. Xavier ${ }^{1}$, A.P. Marques Júnior ${ }^{2,4}$, R.A.C. Leão ${ }^{3}$, P.V.D. Oliveira e Silva ${ }^{3}$ \\ ${ }^{1}$ Aluna de pós-graduação - Escola de Veterinária - UFMG - Belo Horizonte, MG \\ ${ }^{2}$ Escola de Veterinária - UFMG \\ Caixa Postal 567 \\ 30123-970 - Belo Horizonte, MG \\ ${ }^{3}$ Bolsista de Iniciação Científica - Escola de Veterinária - UFMG - Belo Horizonte, MG \\ ${ }^{4}$ Bolsista de Produtividade - CNPq
}

\begin{abstract}
RESUMO
A proporção volumétrica dos constituintes do corpo lúteo foi estudada em 48 ovários de vacas Nelore gestantes, coletados em frigorífico e distribuídos em três grupos, considerando-se o terço da gestação. No primeiro terço, utilizaram-se 11 animais em gestação de até 90 dias; no segundo terço, 20 animais em gestação entre 91 e 180 dias, e no terceiro terço 17 animais em gestação entre 181 e 261 dias. O corpo lúteo foi dissecado e submetido a processamento histológico para avaliação em microscopia óptica. Os animais em gestação de até 90 dias apresentaram maior proporção volumétrica de células endoteliais e pericitos, e nos acima de 181 dias de gestação ocorreu menor proporção de citoplasma (42,7\%) e núcleo $(5,1 \%)$ de células lúteas esteroidogênicas, bem como aumento do tecido conjuntivo e fibroblastos $(47,7 \%)$.
\end{abstract}

Palavras-chave: vaca Nelore, gestação, corpo lúteo, morfometria

\begin{abstract}
The volumetric proportion of the corpus luteum was evaluated in 48 ovaries from pregnant Nelore cows slaughtered in abattoirs, and divided into three groups, considering the trimester of gestation, and classified by the size of the fetus: First trimester - eleven animals with gestation up to 90 days; Second trimester - twenty animals with gestation between 91 and 180 days, and Third trimester - 17 animals with gestation between 181 and 261 days. The corpus luteum was dissected and submitted to histological processing and evaluations under light microscopy. The animals with gestation up to 90 days presented a higher proportion of endotelial cells and pericites. In the Third trimester there occurred a smaller proportion of cytoplasm $(42,7 \%)$ and nucleus $(5,1 \%)$ of steroidogenic luteal cells, and an increase in the conjunctive tissue, fibroblasts (47,7\%).
\end{abstract}

Keywords: Nelore cow, gestation, corpus luteum, morphometry

\section{INTRODUÇÃO}

O corpo lúteo (CL), uma glândula endócrina transitória, durante a sua formação, manutenção e regressão, apresenta características morfológicas distintas (Neves et al., 2002) e passa por intensa remodelação tecidual

Recebido em 1 de março de 2011

Aceito em 11 de maio de 2011

*Autor para correspondência (corresponding author)

E-mail: ampinho@ufmg.br caracterizada por proliferação, diferenciação e morte celular. Possui população heterogênea de células, com características morfofuncionais e bioquímicas distintas, classificadas como células esteroidogênicas e não esteroidogênicas, tais como células endoteliais e pericitos, fibroblastos, macrófagos, mastócitos e leucócitos (Schams e Berisha, 2004; Miyamoto e Shirasuna, 2009). Segundo Fields e Fields (1996), as células não 
esteroidogênicas e o sistema capilar representam $14 \%$ do volume e $53 \%$ das células do corpo lúteo maduro.

As células esteroidogênicas do corpo lúteo são classificadas como células luteínicas pequenas (CLP) e células luteínicas grandes (CLG), identificadas pelo seu tamanho e pelas características funcionais e estruturais (Alila e Hansel, 1984; Fields e Fields, 1996). As CLP originam-se das células da camada da teca interna (Alila e Hansel,1984), apresentam diâmetro médio de $17,2 \mu \mathrm{m}$ e representam cerca de $3,5 \%$ do total de células do CL e $27,7 \%$ do seu volume. Possuem formato estrelado e núcleo irregular em forma de taça, com nucleoplasma densamente corado (O'Shea et al., 1989). As CLG originam-se tanto de células da granulosa quanto de células luteínicas menores (Alila e Hansel, 1984). Possuem diâmetro médio de $38,4 \mu \mathrm{m}$, com formato esférico, núcleo circular grande e centralizado com nucléolo distinto e cromatina dispersa, grânulos de lipídeos e elevado número de grânulos secretórios (Fields et al., 1992; Bertan, 2006), somando cerca de $26,7 \%$ do total das células luteínicas e representando $40,2 \%$ do volume do corpo lúteo (O’Shea et al., 1989).

A fisiologia ovariana de zebuínos foi pouco estudada comparativamente à de taurinos apesar de sua importância para o entendimento de diferenças na fisiologia reprodutiva das subespécies - em relação ao aprimoramento de biotecnias reprodutivas, ao desenvolvimento de estratégias para melhorar as taxas de concepção, ao controle hormonal do ciclo ovariano, à implantação de medidas de manejo e aos tratamentos que minimizem problemas de fertilidade do animal e do rebanho. Na literatura consultada, não foram encontrados trabalhos sobre a proporção volumétrica do corpo lúteo gestacional de vacas Nelore e, em razão disso, neste trabalho avaliaram-se os constituintes do corpo lúteo da vaca Nelore nos três terços da gestação.

\section{MATERIAL E MÉTODOS}

O experimento foi aprovado pelo CETEAUFMG, sob o número 31/2010.

Foram utilizados ovários de vacas da raça Nelore gestantes e saudáveis, abatidas no Frigorífico
Mata Boi, localizado na cidade de Araguari-MG, no Triângulo Mineiro. Os ovários coletados com corpo lúteo foram identificados e divididos em três grupos, considerando-se o estádio de gestação classificado pelo tamanho do concepto. Foi feita uma incisão no corno uterino gestante com exteriorização do feto e corte do cordão umbilical. Posteriormente, o feto foi colocado em decúbito lateral com sua linha dorsal em posição retilínea e mensurou-se o comprimento apicocaudal do feto $(\mathrm{cm})$, da crista nucal (osso occipital) até a primeira vértebra coccígea, para determinação da idade da gestação, aplicando-se a fórmula: $X=2,5(Y+21)$, em que $X$ é a variável "estádio da gestação e $\mathrm{Y}$ representa o comprimento apicocaudal” (Richardson, 1996). Os animais foram distribuídos em três grupos. No primeiro grupo, utilizaram-se 11 animais em gestação de até 90 dias; no segundo, 20 animais com gestação entre 91 e 180 dias, e no terceiro 17 animais com gestação entre 181 e 261 dias.

O corpo lúteo foi dissecado do ovário e imediatamente imerso em solução de formol tamponado a $10 \%$, por período mínimo de quatro horas para prefixação. Após a prefixação, os espécimes foram seccionados em fragmentos de aproximadamente $0,5 \mathrm{~cm}$ de espessura, em plano sagital, do ápice até a base, e mantidos na mesma solução até o processamento. Os fragmentos foram processados segundo a técnica rotineira de inclusão em parafina, cortados em micrótomo à espessura de $5 \mu \mathrm{m}$ e corados pela técnica de hematoxilina e eosina (HE). Os constituintes do corpo lúteo avaliados foram citoplasma e núcleo das células luteínicas, tecido conjuntivo e fibroblastos e células endoteliais e pericitos. As proporções volumétricas foram obtidas pelo método estereométrico, utilizando-se ocular integradora Zeiss KPL 10x, com retículo de cinco linhas horizontais e 25 pontos equidistantes, acoplada a uma objetiva de 40x de um microscópio óptico tradicional. Foram examinados 35 campos por lâmina, escolhidos aleatoriamente, em varredura horizontal, com os resultados sendo expressos em porcentagem sobre um total de 875 pontos por lâmina, segundo Neves e Marques Júnior (2002).

O delineamento experimental foi inteiramente ao acaso, sendo os resultados submetidos à análise de variância e as diferenças entre médias comparadas pelo teste $\mathrm{t}(\mathrm{P}<0,05)$. 


\section{RESULTADOS E DISCUSSÃO}

Os valores médios da proporção volumétrica dos constituintes do corpo lúteo são apresentados na Tab. 1.

Os resultados mostram diferença significativa na proporção volumétrica para citoplasma e núcleo das CLG e CLP nos três terços de gestação $(\mathrm{P}<0,05)$. Ainda, mostram consistência na diminuição, a cada terço, do CCL, comparandose com o encontrado para NCL, o que demonstra a coerência do método utilizado. Os resultados revelam redução das células esteroidogênicas, observada desde o primeiro terço de gestação, embora com menor intensidade em relação ao último. Segundo Fields e Fields (1996), somente após 200 dias de gestação é que se observa elevado declínio das células esteroidogênicas, devido ao processo de luteólise. Embora a diminuição do percentual das células luteínicas, observada neste experimento, aparentemente não interfira na atividade mínima do CL para manter a gestação, estudos são necessários para verificar se esta diminuição ocorre também no animal não gestante. $\mathrm{O}$ futuro entendimento desse evento fisiológico poderia contribuir para o desenvolvimento ou a ampliação e o refinamento de métodos utilizados em biotecnias reprodutivas que demandam o controle do corpo lúteo em zebuínos, na busca de terapêutica de indivíduos ou para incrementar a produtividade do rebanho.

Tabela 1. Médias e desvios-padrão da proporção volumétrica (\%) do citoplasma das células luteínicas (CCL), núcleo das células luteínicas (NCL), células endoteliais e pericitos (CE e P) e tecido conjuntivo e fibroblastos (TC e F) do corpo lúteo de vacas Nelore gestantes no primeiro (0-90), segundo (91-180) e terceiro (181-261) terços da gestação

\begin{tabular}{ccccc}
\hline Terços de gestação & CCL & NCL & CE e P & TC e F \\
\hline $0-90$ & $54,9 \pm 6,3 \mathrm{a}$ & $10,0 \pm 3,0 \mathrm{a}$ & $1,7 \pm 1,1 \mathrm{a}$ & $29,3 \pm 7,4 \mathrm{c}$ \\
$91-180$ & $48,7 \pm 6,6 \mathrm{~b}$ & $6,8 \pm 2,0 \mathrm{~b}$ & $0,2 \pm 0,3 \mathrm{~b}$ & $40,0 \pm 7,2 \mathrm{~b}$ \\
$181-261$ & $42,7 \pm 7,5 \mathrm{c}$ & $5,1 \pm 1,5 \mathrm{c}$ & $0,1 \pm 0,1 \mathrm{~b}$ & $47,7 \pm 8,0 \mathrm{a}$ \\
\hline
\end{tabular}

Números com letras diferentes na mesma coluna diferem entre si $(\mathrm{P}<0,05)$.

Para as células endoteliais e pericitos, verificouse que houve maior porcentagem destas no primeiro terço de gestação, em relação aos dois terços seguintes, refletindo o processo de angiogênese, importante para a formação e o desenvolvimento adequado do CL, pois o fluxo sanguíneo cresce gradualmente, à medida que aumentam o volume do corpo lúteo e sua produção de progesterona (Acosta et al., 2003).

Os resultados mostram aumento gradativo do tecido conjuntivo e fibroblastos com o avanço da gestação. Neves e Marques Júnior (2006) encontraram maior proporção de tecido conjuntivo e fibroblastos em vacas Nelore gestantes $(48,1 \%)$ comparadas com as não gestantes (38,8\%), sem, contudo, avaliarem a proporção ao longo da gestação. Wiltbank e Niswender (1992) descreveram que, durante o processo de regressão, o corpo lúteo passa por intensas modificações estruturais até a formação do tecido cicatricial denominado corpus albicans, com proliferação de fibroblastos e deposição de matriz extracelular.

\section{CONCLUSÕES}

Em vacas Nelore gestantes, o corpo lúteo de até 90 dias apresenta maior proporção de células endoteliais e pericitos; há redução do número de células esteroidogênicas a partir do segundo terço de gestação e ocorre, no terceiro terço, menor proporção de citoplasma e núcleo de células lúteas esteroidogênicas, maior número de células em degeneração e aumento do percentual de tecido conjuntivo, fibroblastos e matriz extracelular, entretanto as modificações histológicas não representam risco fisiológico que comprometa a viabilidade da gestação.

\section{AGRADECIMENTOS}

Ao $\mathrm{CNPq}$, pelo apoio financeiro via Grant Pesquisador, e à FAPEMIG. 


\section{REFERÊNCIAS BIBLIOGRÁFICAS}

ACOSTA, T.J.; HAYASHI, K.G.; OHTANI, M. et al. Local changes in blood flow within the preovulatory follicle wall and early corpus luteum in cows. Reproduction, v.125, p.759-767, 2003.

ALILA, W.; HANSEL, W. Origin of different cell types in the bovine corpus luteum as characterized by specific monoclonal antibodies. Biol. Reprod., v.31, p.1015-1025, 1984.

BERTAN, C.M.; CESAR, M.C.; PUGINE, S.M.P. et al. Indução da ovulação em vacas com gonadotrofina coriônica humana (hCG) purificada por cromatografia de afinidade. Braz. J. Vet. Res. Anim. Sci., v.43, p.379-386, 2006.

FIELDS, M.J.; BARROS, C.M.; WATKINS, W.B. et al. Characterization of large luteal cells and their secretory granules during the estrous cycle of the cow. Biol. Reprod., v.46, p.535-545, 1992.

FIELDS, M.J.; FIELDS, P.A. Morphological characteristics of the bovine corpus luteum during the estrus cycle and pregnancy. Theriogenology, v.45, p.1295-1325, 1996.

MIYAMOTO, A.; SHIRASUNA, K. Luteolysis in the cow: a novel concept of vasoactive molecules. Anim. Reprod., v.6, p.47-59, 2009.

NEVES, M.M.; MARQUES JR, A.P. Tamanho da amostra para estudo da proporção volumétrica dos constituintes do corpo lúteo bovino. Arch. Vet. Sci., v.7, p.81-85, 2002.
NEVES, M.M.; MARQUES JR, A.P. SANTANA, C.V. et al. Características de ovários de fêmeas zebu (Bos taurus indicus) colhidos em abatedouro. Arq. Bras. Med. Vet. Zootec. v.54, p.651-654, 2002.

NEVES, M.M.; MARQUES JR, A.P. Proporção volumétrica dos constituintes do corpo lúteo de Nelore. Arq. Bras. Med. Vet. Zootec., v.58, p.944-946, 2006.

O’SHEA, J.D.; RODGERS, R.J.; DÓCCHIO, M.J. Cellular composition of the cyclic corpus luteum of the cow. J. Reprod. Fertil., v.85, p.483-487, 1989.

RICHARDSON, C. The development of the conceptus - Personal communication. In: ARTHUR, G.H.; PARKINSON, T.J. (Eds.). Veterinary reproduction and obstetrics. 8.ed. London: WB Saunders, 1996. p.68.

SCHAMS, D.; BERISHA, B. Regulation of corpus luteum function in cattle - an overview. Reprod. Dom. Anim., v.39, p.241-251, 2004.

WILTBANK, M.C.; NISWENDER, G.D. Functional aspects of differentiation and degeneration of the steroidogenic cells of the corpus luteum in domestic ruminants. Anim. Reprod. Sci., v.28, p.103-110, 1992. 